\title{
OS YOUTUBERS E AS RELAÇÕES DE IDENTIFICAÇÃO E PROJEÇÃO NO IMAGINÁRIO INFANTO-JUVENIL CONTEMPORÂNEO: DISCUSSÕES A PARTIR DA ÉTICA DA ESTÉTICA
}

\author{
Heloisa Juncklaus Preis Moraes ${ }^{1}$
}

\section{Imaginário: identificação e projeção de uma imagem²}

Preferimos sempre começar a falar do Imaginário pela sua potência. Enquanto seres simbólicos, usamos o nosso imaginário para forjar imagens, logo, estas não são destituídas de um potencial criador. Para a antropologia do imaginário, teoria na qual debruçamos nossas pesquisas, há certa convergência, isomorfismo e totalidade das imagens expressas pelo ser humano. Das primeiras representações, passando pelas antigas mitologias às narrativas contemporâneas, podemos encontrar matrizes: arquétipos e símbolos são mobilizados pelos mitos. O imaginário, para Durand (2002), é a matéria prima do espírito. Confere a capacidade ao ser humano de formular atitudes imaginativas para enfrentar a consciência da finitude. Sua expressão se dá pela imaginação criadora: dinamismo organizador da representação. Três conceitos básicos orbitam esta teoria: imagem, imaginação e imaginário. Strôngoli (2013: 118) nos ajuda a entendê-los:

\footnotetext{
a imagem é a representação de realidades do mundo físico, mental e emocional; a imaginação, a faculdade de perceber, reproduzir e criar essas imagens; o imaginário, a maneira como tal faculdade é operacionalizada para construir o repertório das experiências sensíveis e inteligíveis de cada indivíduo.
}

O modelo científico da modernidade, baseado em uma visão racional, está esgotado. Trazendo o conceito de Durand (1996) de bacia semântica tal como o "conjunto homogêneo de representações que manifestam o imaginário sócio-cultural de uma época", podemos dizer que esta oferece impressões de paisagem cultural e de atualidade. A bacia semântica é ambiente para o trajeto antropológico. Este, nas palavras de Durand (2002: 41), configura-se como "a incessante troca que existe ao nível imaginário entre as pulsões subjetivas e assimiladoras e as intimações objetivas

\footnotetext{
${ }^{1}$ Universidade do Sul de Santa Catarina, Brasil.

2 Artigo produzido a partir dos resultados da pesquisa "A vivência do virtual por crianças de baixa renda em Tubarão, Santa Catarina: panorama de uma década”, com apoio do CNPq.
} 
que emanam do meio cósmico e social". Ou seja, há um polo mais pulsional, em que estão presentes os schèmes e arquétipos, símbolos e mitos, que sugestionam a expressão simbólica, variando com as intimações do meio sociocultural num dado tempo e espaço de experiências compartilhadas, tal como veremos nos relatos das crianças.

Assim, quando falamos de imaginário remetemos a noção às palavras de Teixeira (1999: 22) que este "é a própria experiência de vida expressando-se em sistemas e práticas simbólicas". Azevedo (2016), em seu relato de pesquisa que discute imaginário e as redes sociais, destaca que há uma mudança de paradigma frente às tecnologias, não mais pelas suas ferramentas técnicas e ao que isso nos proporciona, mas, especialmente, pela ação impulsionada pela emoção fundamentada na sedução, o prazer imediato. O autor vai além, ao esboçar as mudanças físicas, mas também cognitivas dessas transformações: "através do que somos e do como fazemos, momento a momento, dia a dia, consciente ou inconscientemente, alteramos os fluxos químicos nas nossas sinapses e modificamos nosso cérebro" (Azevedo, 2016: 97). Essa questão é importante quando nos deparamos com situações, inúmeras, em que as tecnologias remodelam as atividades e os sentidos que damos a elas. Os conteúdos acessados e sua forma de articulação e sentido demandam estratégias outras, capacidades cognitivas até então desconhecidas. Outras linguagens, outros processos de significação, outras imagens-mundo. São as modulações das configurações sócio-culturais como um dos pólos do trajeto antropológico.

Este processo necessita de uma aprendizagem cognitiva, afetiva e até psicomotora para todas essas transformações, embora as crianças e jovens absorvam e ressignifiquem esta prática de modo muito mais natural. $\mathrm{O}$ fato é que há uma mudança no formato de trocas simbólicas na cultura contemporânea, profusão de imagens e tecnologias da imagem e no tipo de conteúdo expresso: "a convergência das mídias, toda essa dinâmica tem provocado alterações em nossos modos de socialização e subjetivação, impactando nossa relação com o mundo, com o outro e conosco" (Monteiro, Lima e Silva, 2016: 202).

Azevedo (2016: 107) nos alerta que "o avanço da utilização da tecnologia vem se dando não somente pelas facilidades que permite como uma extensão das capacidades humanas, mas, também, porque passou a ser no imaginário social do brasileiro um objeto de desejo, como um indicador de status social e intelectual". E é por este ambiência que tratamos, a seguir, das relações entre ética da estética (Maffesoli, 
1999) e o imaginário infanto-juvenil contemporâneo ligado aos youtubers como espírito do tempo pertencente a bacia semântica da pós-modernidade, uma vez que:

A noção de bacia semântica, proposta por Gilbert Durand e inspirada do inconsciente coletivo de Jung, é igualmente uma noção interessante a considerar. Gilbert Durand utiliza a imagem da bacia semântica para indicar como as pequenas coisas vão gerar as coisas mais importantes. A inundação acaba por originar o rio embaixo do vale, rio que vamos nomear, que vamos canalizar, e que vai, finalmente, perder-se no delta, depois se lançar no mar até que um novo ciclo recomeça" (Maffesoli, 2004: 24).

No que tange à ética da estética, cabe dizer que esta se refere ao espírito coletivo da pós-modernidade. Nela, a diversidade de valores e modos de vida é considerada, estilizada e compartilhada. Reflete-se na arte e no conhecimento produzido na contemporaneidade. Cada época, segundo Maffesoli (1999) tem suas ideias obsedantes, que são expressas dos mais variados modos ou expressões societais, quer seja pela literatura, modos de vida, expressões culturais e ideológicas (políticas, jornalísticas ou eruditas). Por vezes, para o autor, esta ideia obsedante, aquilo que fundamenta e permite o estar-junto, é o dever-ser, o que Maffesoli (1999: 25) chama de morale stricto sensu, valorizando "o projeto, a produtividade e o puritanismo". Outras vezes, ao contrário, "vai valorizar o sensível, a comunicação, a emoção coletiva... será então, uma ethica". Define o autor, "moral versus ética", pra formular a expressão ética da estética. E uma estética presente na ambiência social:

De fato, não é mais possível reduzir a arte apenas às grandes obras qualificadas geralmente de culturais. É toda a vida cotidiana que pode ser considerada uma obra de arte. Por causa da massificação da cultura, com certeza, mas também porque todas as situações e práticas minúsculas constituem o terreno sobre o qual se elevam cultura e civilização (Maffesoli, 1999: 26).

As ações e expressões do dia a dia colocam em cena as emoções coletivas, fazem emergir o estar junto e as marcas de uma época, pois estão plenas de sentido, ainda que criticadas pela falta de finalidade. Forma profana de religião, conceitua Maffesoli (1999: 27), ao retornar o termo originário religare e aproximá-lo da expressão de Nietzsche, "a vontade de poder enquanto arte". E complementa: 
É isso que pode servir de pano de fundo à estética e a sua função de ética. O fato de experimentar em comum suscita um valor, é vetor de criação. Que esta seja macroscópica ou minúscula, que ela se ligue aos modos de vida, à produção, ao ambiente, à própria comunicação, não faz diferença. A potência coletiva cria uma obra de arte: a vida social em seu todo, e em suas diversas modalidades. É, portanto, a partir de uma arte generalizada que se pode compreender a estética como faculdade de sentir em comum. Ao fazer isto, retomo a concepção que Kant dava à aesthesis: a ênfase, sendo colocada menos sobre o objeto artístico como tal, que sobre o processo que me faz admirar este objeto (Maffesoli, 1999: 28).

As culturas dos sentimentos, afirma o sociólogo francês, podem ser imorais frente às normas estabelecidas, mas seu devir, instrutivo: "de início são combativas, depois toleradas, em seguida aceitas, e, enfim, pouco a pouco capilarizam-se no conjunto do corpo social". (Maffesoli, 1999: 37). Este processo é o que permite a compreensão, por Maffesoli, do deslize de uma lógica da identidade (essência individualista) para uma lógica de identificação (essência coletiva). Nesta, a "tal" cultura de sentimentos, ou seja, consequência de atração: a agremiação vem de acordo com as ocorrências e os desejos. Esta passagem conceitual vem ao encontro da análise que se propõe sobre o imaginário infanto-juvenil e a imagem de youtubers como símbolo de desejo, identificação e projeção, desta geração. À esta conjunção, Maffesoli (1999: 37) faz a ligação com o conceito de ética: "o valor, a admiração, o 'hobby', o gosto que são partilhados tornam-se cimento, são vetores de ética".

Assim, o autor denomina ética: "uma moral 'sem obrigação nem sanção'; sem outra obrigação que a de unir-se, de ser membro de corpo coletivo, sem outra sanção que a de ser excluído, se cessa o interesse (inter-esse) que me liga ao grupo". E, sintetiza, conceituando a expressão da qual nos apropriamos para a análise: "eis a ética da estética: o fato de experimentar junto algo é fator da socialização" (Maffesoli, 1999: $37)$.

Maffesoli (1999) nos apresenta uma relação entre ética e estética, na medida em que o valor tribal que fundamenta o que ele chama de narcisismo coletivo é causa e efeito de um mundo de vida (não consciente). O sociólogo coloca em discussão a lógica societal, não redutível (nem à razão, à consciência ou ao indivíduo, nem a um saber de estatuto científico), mas "a oscilação entre o conhecimento e a vida cotidiana, entre o espírito e o sentido" (Maffesoli, 2007: 12). Utilizando como metáfora os títulos de suas publicações, navega entre o conhecimento comum e a razão sensível. O autor versa sobre esta ambiência: "é fato que o ético, fundamento do vínculo social, depende estruturalmente do estético: é essa capacidade de experimentar emoções, compartilhá- 
las, transformá-las em cimento de toda a sociedade" (idem). Para o autor, a vida contemplativa dá, aos poucos, lugar à vida ativa, uma oportunidade de expressar e questionar as nossas convicções, através de nossos mitos e símbolos.

E é no que se refere a esse olhar plural que ocorre a confluência de ideias entre Martino (2007) e Maffesoli (2007; 2010). A socialidade, para Maffesoli, é comunhão e percepção da necessidade de o artista (e também o comunicador e qualquer ator social), de estar conectado ao cotidiano. Para o estudioso francês, portanto, a identidade fixa e definida, na sociedade contemporânea, dá lugar às diversas identificações. As posições fixas, os padrões tidos como "incontestáveis" e a ideia de referência única estão obsoletas.

Para Silva (2006: 13), a construção do imaginário individual se dá por em três momentos: identificação, apropriação e distorção. O primeiro, é o reconhecimento de si no outro, o segundo, desejo de ter o outro em si e, por fim, reelaboração do outro para si. O imaginário social, por contágio, disseminação e imitação. O contágio, seguindo a lógica tribal, é a aceitação do modelo do outro; a disseminação, percebe-se a igualdade na diferença; e, a imitação prevê a distinção do todo por difusão de uma parte.

Segundo Maffesoli (1995: 36), só é possível viver "pelo olhar e pela palavra do outro". Isso é o estilo, a vida social em curso. Preconizam-se, aqui, o vínculo e o pertencimento a um grupo, sendo o estético o cimento social que daria à sociedade o caráter coletivo. Martino (2007), por sua vez, destaca que uma comunicação é um ato estético na medida em que denota uma reconstrução poética de uma sensação que se pretende externar, expressar para além de si mesmo e compartilhar, causando sensação similar noutro indivíduo.

$\mathrm{Na}$ atualidade, frisa Silva (2006), o que mantém a socialidade é mais a mística do que a mera política (jogo de interesses e, portanto, de poder). "Ou seja, a potência simbólica que organiza o social a partir de um imaginário cultural" (Silva, 2006: 34). Segundo Martino (2007), a noção de habitus, proposta por Bordieu e que origina o conceito de estilo de Maffesoli, que tem no signo elementos de excelência de comunicação e de operação mental, indica as etapas da trajetória social do indivíduo. Conduz as relações sociais e dá sentido a elas. Assim, o habitus mental individual é construído de acordo com as vivências e práticas intelectuais de cada um para compor o habitus coletivo (Martino, 2007). Este se faz presente nas abordagens da estética dos 
media atuais. Formando, em um espectro mais coletivo, e em nosso caso especialmente, o imaginário infanto-juvenil contemporâneo.

A imagem é estruturante neste contexto. Não nos referimos somente à imagem estática, mas a imagem-mundo. Se partirmos do pressuposto que a mídia e seus dispositivos tecnológicos são a mais importante produtora de efeitos de sentido sobre a realidade ou, ao menos, seleciona os fatos a serem discutidos socialmente, também é importante destacar que muito desta seleção nos chega através de imagens. Não só imagens materiais, mas imagens-conceito, imagens enquanto valor. Criação imaginal para a partilha do sensível, marca da socialidade contemporânea. Mescla paradoxal entre o impalpável e o real que faz sentido, como veremos adiante no relato das experiências.

\section{Culturanálise de um grupo infanto-juvenil}

Nas primeiras páginas de Polegarzinha (2013), Serres nos alerta para o fato de que "antes de ensinar o que quer que seja a alguém, é preciso, no mínimo, conhecer esse alguém”. Essa passagem fez lembrar o espanto de uma das professoras de um dos grupos analisados ao ouvir a realidade relatada. "Não sabia que era assim. Não fazia ideia”, disse a docente, com 32 anos de profissão ao se dar conta de que seus alunos de 9 ou 10 anos, habitam o virtual.

Serres (2013) contextualiza que não habitamos mais o mesmo lugar desses jovens e crianças: a relação com o mundo mudou, assim como o conhecimento, as imagens-mundo. Há novos laços sociais que a geração anterior a esta não contempla. Aquela professora leciona conteúdos em plataformas cognitivas que não atraem para sujeitos também transformados. O autor, assim como Azevedo (2016), fala de uma mudança cognitiva:

As ciências cognitivas mostram que o uso da internet, a leitura ou a escrita das mensagens como polegar, a consulta à Wikipédia ou ao Facebook não ativam os mesmos neurônios nem as mesmas zonas corticais que o uso do livro, do quadronegro ou do caderno. Essas crianças podem manipular várias informações ao mesmo tempo. Não conhecem, não integralizam nem sintetizam da mesma forma que nós, seus antepassados. (Serres, 2013: 19). 
Aliando a perspectiva teórica do Imaginário com as manifestações culturais contemporâneas, buscamos um recorte metodológico coerente: a Culturanálise de Grupos, proposta por Paula de Carvalho (1991) e utilizada por Cecília Sanchez Teixeira (1999a). A autora (1999a: 23) nos esclarece: “é um instrumento de sócio-diagnóstico que permite a apreensão da cultura de grupos (e do imaginário que nela se manifesta) tanto em seu nível patente, instituído, como em seu nível latente, instituinte". Assim trazendo as indicações de seu proponente, quanto a sua operacionalização:

a descrição e o inventário da paisagem cultural do grupo deve ser, numa primeira etapa, fenomenológica, por meio de um mapeamento da cultura patente (ideário, ideações, códigos, sistemas de ação, formações discursivas, modos de pensar e agir) e, numa segunda etapa, analítica, pelo mapeamento da cultura latente (imaginário, fantasmatizações, vivências, vínculos afetuais, modos de sentir (Paula de Carvalho citado por Teixeira, 1999a: 23).

Segundo esta proposta, a partir do que apreendemos entre o patente e o latente, ou seja, na relação entre os dois pólos, surge a cultura emergente. Nesta pesquisa, parece configurar uma cultura emergente do culto aos youtubers, como espírito do tempo contemporâneo.

Ouvimos dois grupos de crianças de quintos anos de duas escolas públicas - uma municipal e uma estadual - em Tubarão, sul de Santa Catarina. Ao total, foram crianças na faixa etária de 10 anos. O principal mitema nas conversas sobre tecnologias com este público, identificamos a palavra youtuber como recorrência unânime. Esta recorrência simbólica está ancorada na admiração, identificação e projeção da imagem dos youtubers como prática cotidiana, ideal de personalidade e função social.

Dos alunos que participaram da pesquisa, a maioria tem celular próprio, sendo que todos tem acesso à Internet em casa, e afirmaram que podem ficar conectados o tempo que quiserem. "Posso ficar o tempo que eu quiser", disse uma aluna, seguida de vários outros que fizeram a mesma afirmação. Alguns disseram que tem que fazer tarefa primeiro, mas ficam com o celular por perto, no silencioso. Segundo eles, os pais só reclamam quando não há cumprimento ou quando há atraso de uma ordem como almoçar ou tomar banho.

Percebemos uma prevalência dos aparelhos tecnológicos na vida das crianças. $\mathrm{O}$ acesso aos conteúdos e socialidade virtual é prática cotidiana e instauradora de mudança nos hábitos de todas as atividades diárias. O dispositivos, especialmente o celular, aparecem como uma extensão das próprias crianças. O distanciamento é improvável, 
quase impossível. A discussão foi relevante, por exemplo, quando falamos dos estudos. Aparecem, nas falas das crianças, por exemplo: "ajuda e atrapalha, porque quando vou fazer tarefa, começa a apitar a mensagem do whatsapp", "não consigo ficar sem celular", "desligo, deixo longe, no silencioso", “qualquer coisa, paro e espio o celular", "tipo, se eu erro, passo corretivo e até secar vou olhar o celular", "eu copio mais rápido para ver o celular". Percebemos que há uma ansiedade geral para ter contato com o celular.

Todos assistem a vídeos no YouTube, jogam e participam de redes sociais, alguns já tem seu próprio canal, então gravam, editam e postam vídeos. Nesta plataforma, a preferência unânime, como já afirmamos, são os youtubers. Alguns citados foram: Resende, Bibi, Bel Matheus, Luba, Roberta Pupi, Tarciele, Kéfera, Vinícius Game e Wenderson. “Acho legal, porque não tem nada para fazer”, relatou uma aluna. Os canais passam a ideia de ação, são engraçados, usam palavras não adequadas, muitos tem um estilo louco, dão sustos, e apresentam surpresas. Foram essas as motivações mais destacadas para a preferência dos canais de YouTube.

Quando postam vídeos, sentem-se "aliviados" e "engraçados". A identificação e projeção eram nítidas na vontade das crianças em querer ser tal como os ídolos que seguem. A pergunta sobre o que eles desejam fazer no futuro era sempre envolvendo esta imagem: um youtuber, um youtuber famoso, um famoso da internet. "Queria ficar famoso", "espera que as pessoas gostem do meu canal e, do que elas gostam mais, faço mais daquele vídeo. Mais e mais".

$\mathrm{Na}$ conversação sobre este tema, as crianças mostraram-se animadas, sendo difícil, por vezes, exigir uma ordem de fala. Houve uma necessidade de expor cada um sua experiência, seus sentimentos. De maneira geral, não encontram nenhuma restrição de tempo, acesso ou conteúdo por parte dos pais ou responsáveis. Um único relato foi de um menino que o acesso ao canal da youtuber Kéfera foi proibido por seus pais, que ameaçaram trancá-lo no quarto sem celular, em função dos palavrões que a protagonista fala. Embora uma outra aluna contrapôs e disse que sua mãe também era fã desta youtuber e assistiam aos vídeos juntas. 
Todos conheciam o conterrâneo Luba e relataram o sonho de conhecê-lo e colocam sua expectativa de que o encontro seja obra do acaso, "por sorte", denotado a imagem de celebridade inalcançável. Para entender um pouco mais desta manifestação cultural contemporânea, entrevistamos o youtuber do LubaTV para pensarmos o lado da criação.

\section{Youtubers: imagem-símbolos de uma geração}

Ao longo dos últimos anos, esta profissão tem crescido muito. "Pessoas comuns" que se dedicam em postar vídeos e que despontam pela audiência e popularidade. São seguidas virtualmente por milhões de pessoas. Os youtubers tem um emprego sem carteira assinada e sem cobrança de serviços que a Google oferece pra quem tem uma audiência crescente dentro do YouTube. Os canais usam descontração, linguagem coloquial, erros, mostram desafios, demonstram produtos. Já há certa segmentação: jogos, beleza, desafios, literatura, entretenimento, humor, sátiras e paródias. Os vídeos geralmente são curtos e tem uma frequência de postagem, o que garante a assiduidade dos seguidores.

Para entender um pouco deste universo, entrevistamos o Luba, Lucas Rossi Feuerschütte, do canal Luba TV, um dos mais citados pelos sujeitos da pesquisa. Em 2016, ele foi eleito a sexta pessoa mais influente da Internet e TV pelo Meio $e$ Mensagem, portal de Publicidade e Propaganda. Tem lotado teatros Brasil à fora com a LubaFest, espetáculo solo cujo objetivo é "trazer o fã para o universo do Luba" (LubaTV, 2017). Cada apresentação dura uma hora e meia em que o youtuber conta sobre sua vida, seu cotidiano e sua trajetória, por meio de conversas e brincadeiras, ao estilo de suas produções. Em 2016, a LubaFest percorreu 13 estados e, em 36 edições, ultrapassou os 27 mil espectadores. O canal LubaTV, além de vídeos e jogos, tem o Amazing Project - projeto social, e loja de produtos Luba.

Em março de 2017, o canal Luba TV atingiu 4 milhões de inscritos e ganhou o Prêmio Internacional como Personalidade Brasileira Favorita, pelo Kids Choice Awards. Juntamente com outros youtubers, cobriu um dos maiores festivais de inovação do mundo, o SxSw - South by Sothhwest. Esses dados demonstram as manifestações sociais que repercutem este novo ator social e midiático. Como já nos disse Meffesoli 
(2004), as pequenas transformações no cotidiano é que vão dar a escorrência e o esgotamento na bacia semântica.

Para Luba (2016), o sucesso dos youtubers é um fenômeno, embora compreensível. "Acredito que as pessoas (principalmente os mais jovens) procuram "ídolos" mais próximos e que conseguem representá-los e 'falar a mesma língua",, destacou. Para a produção dos vídeos, feitos a um público especialmente entre 16 e 24 anos, mas cada vez mais precoce, não há uma técnica específica. Ele mesmo planeja o vídeo, grava, edita e publica, sendo que a única estratégia é a postagem diária. Os de maior sucesso são os mais pessoais: "acredito que são os que as pessoas mais se identificam e por isso são mais populares". Esse parece ser o grande viés destas produções: mostrar-se em atos corriqueiros do cotidiano, deixar transparecer, como diria Maffesoli, o homem sem qualidade. Só que, de maneira geral, com o uso do humor como ingrediente principal. Marca da descontração.

Quando questionado se ele percebe que é modelo para muita gente, que se identifica e projeta na sua imagem, o youtuber afirma que sim e que encara isso com responsabilidade: "meu objetivo principal é sempre entreter, mas acredito que, com os meus vídeos, consigo influenciar as pessoas a serem mais educadas, bondosas e com menos (de preferência zero) preconceitos". Mas, o porquê do poder de mobilização da sua imagem, não teve resposta: "Boa pergunta! Difícil também, porque eu não sei”.

Quando tratamos de futuro, Luba disse que percebe a expectativa infanto-juvenil com dúvidas: "A cada ano que passa, percebo que a pressão de fazer alguma coisa, ser alguém e justamente escolher essas coisas aumenta. Acredito que eles precisam de alguém que diga: "respira, vai dar tudo certo". E que as tecnologias podem auxiliar o processo criativo de crianças e jovens com o conhecimento disponível: "a internet, principalmente, ajuda você a adquirir conhecimento sobre alguma coisa que você quer aprender. As tecnologias ajudam as pessoas a se tornarem autodidatas, principalmente as que não tem acesso ao ensino, mas, pela inclusão digital, tem acesso à internet, por exemplo. Assim, é mais fácil”. Este fácil da frase anterior veio grafado com várias aspas, para chamar a atenção de quanto é importante "você perseguir o seu sonho". É com este tom de otimismo, conselheiro, de alguém que alcançou a popularidade que o youtuber se reporta aos seus telespectadores, seguidores e fãs. Uma legião de meninos e meninas que se identifica e projeta seus desejos na sua imagem. Não tratamos da 
imagem física, mas na imagem que um youtuber de sucesso representa e a toda força simbólica que ela carrega.

É comum vermos crianças com a linguagem, verbal e não-verbal, dos youtubers. Gravações domésticas podem começar com o clichê "olá, pessoal” e finalizar com um "se gostou do vídeo, dá um like e se inscreve no canal". Tal qual como o resultado da pesquisa de Azevedo (2016) em relação às redes sociais incorporada como mais um elemento do cotidiano, o acompanhamento de canais dos youtubers também é uma prática recorrente e intensa no dia a dia dos jovens sujeitos desta pesquisa.

Fato reforçado pelo agendamento do tema em outras tecnologias do imaginário, como o jornalismo e a publicidade, por exemplo. Recém lançada campanha de divulgação do ENEM 2017 pelo Ministério da Educação mostra jovens com aparelhos tecnológicos em diversas situações de autoria nos registros. "É, o mundo mudou. Agora, todo mundo é gerador de conteúdo. Entrar ao vivo não é mais privilégio da TV. É um privilégio seu. Você também dá notícia, Você também tem audiência... Tem voz". Cenas de alegria, diversão, mostram-se como ambiência de potência. Especialmente pelo público a quem se destina: só em 2016, foram mais de cinco milhões de jovens inscritos no Exame.

Também a revista Época Negócios (2017) lançou a matéria "O poder da indústria dos youtubers", que inicia relatando um dia de casa lotada e a aglomeração de fãs para ver o show do Luba, o youtuber com 460 milhões de visualizações. Afirma o texto jornalístico, que chama a atenção para o negócio que gira ao redor desta nova prática social:

Luba é parte de uma onda crescente de youtubers que dominam a web. Há quem prefira chamá-los de influenciadores digitais, criadores de conteúdo ou simplesmente "creators". Seja lá qual for a nomenclatura, é inegável que essas pessoas, todas jovens (entre as mais populares, a maioria tem entre 20 e 28 anos), têm mudado a forma como a garotada consome vídeo, atraído o mercado publicitário e diversificado suas fontes de renda para fazer da própria imagem um negócio lucrativo. Viraram empreendedores de si mesmos - ainda que sem querer e criaram uma indústria ao seu redor.

As características da maioria dos canais giram em torno da descontração, humor, colocar-se em situações desafiadoras e engraçadas que permitem "rir de si mesmos". E a popularidade só cresce, sendo medida pelo número de seguidores. Ter uma câmera e gravar-se em ambiente caseiro e em situações cotidianas dá o sentido de possibilidade, 
potência. Experiência que permite passar do erro à errância e, ainda, diante disso, permitir-se ao riso. Riso de si, riso do outro. "Colocar o humano num movimento de produção, numa existência em devir, na qual se constrói, constrói o mundo e o outro, em incessante variação" (Monteiro, Lima e Silva, 2016: 202). Sensibilidade e imaginação como prática do cotidiano, de pertencimento e projeção. E, ainda, a linguagem - verbal e não-verbal, como potência de produção.

\section{Trilhando o caminho da potência imaginativa e imaginante}

O espírito do tempo, unânime nas crianças ouvidas nos dois ambientes, é que o melhor da tecnologia é o YouTube e os canais de youtubers. As tecnologias de sedução ao Imaginário Social atingem o caráter ético (motivação) e o estético (apreciação) das produções, ainda que um vídeo bem produzido é sempre mais assistido. O caráter estético é essencial para conquistar a audiência. O ético, para mantê-la. Questões como humor, desafios, popularidade são destaques na apreciação da audiência.

Há um imaginário infanto-juvenil totalmente voltado para a imagem dos youtubers, seja como audiência, o que inclui mudanças na rotina cotidiana imediata, ou, além disso, como prática de médio e longo prazo, quando a identificação leva a projeções de futuro. Já se percebe, tal como identificado nos ambientes da pesquisa, que há uma disparidade entre o que chama a atenção das crianças e jovens. Entre a tecnologia e a sala de aula, o desejo de atenção para aquela é muito maior. A tecnologia mostra-se mais atraente (e acessível). Pensando nisso, temos um desdobramento desta pesquisa, com o propósito de discutir não só o caráter semântico das imagens, mas também o afetivo e todo o seu potencial.

Assim, as ações desenvolvidas frente aos dados da pesquisa têm por objetivo contextualizar este cenário que envolve as tecnologias e as crianças e jovens, bem como apresentar ferramentas de criação de canais no YouTube como prática de inovação pedagógica, aproximando o interesse e competência infanto-juvenil de criação e autonomia para assuntos e reflexão de conteúdos curriculares. As ações ${ }^{3}$ desdobradas tem envolvido professores do ensino fundamental com interesse em conhecer e aplicar

\footnotetext{
${ }^{3}$ Oferta do minicurso "A imagem da descontração: canais infanto-juvenis no youtube como prática de inovação na escola”, no VIII Simpósio de Formação de Professores, para professores da rede pública, realizado na Universidade do Sul de Santa Catarina, em 2016.
} 
tais ferramentas na prática escolar. Nossa intenção é propor a realização ${ }^{4}$ de canais no YouTube como possibilidade de inovar na educação, apostando no caráter semântico e afetivo da imagem, o que criaria vínculo, pertencimento, prazer, cumplicidade e autonomia nas ações de apreender. A reflexão sobre o imaginário infanto-juvenil frente às tecnologias é nossa problemática de pesquisa há muitos anos quando, no início dos anos 2000 pesquisávamos, sempre em escolas públicas, a descoberta e a vivência do virtual (Moraes, 2012). Se, à época, a prática estava mais voltada à descoberta, hoje percebemos que o próprio imaginário mudou. Antes, uma visão instrumental; hoje, muito mais poiética, possibilidade de colocar-se como produtoras: algumas já em seus canais, outras, como projeção de futuro. Embora todas tendo os youtubers como imagem símbolo de identificação.

Sabemos, pela perspectiva do Imaginário, que a imagem tem a capacidade de mobilizar afetos, memória, percepções. O homem é um ser simbólico e organiza a realidade a partir do imaginário. Contrera (2005) nos alerta para o que chama de "armadilha do nosso tempo", aquela que nos faz crer, pela força do sistema dos objetos, que todo o sonho é representável. Lança a necessidade de buscarmos o potencial, esquecido, da imaginação. Em síntese, porque não podemos esquecer que estamos tratando do trajeto antropológico (Durand, 2002) destes jovens e crianças, e devemos levar em consideração as "pulsões subjetivas e assimiladoras do sujeito" em relação dialógica com "as pulsões subjetivas e assimiladoras do meio cósmico e social”. E estes indivíduos estão produzindo este seu trajeto, servindo de dispositivos poiéticos que "lhes permitem construir mundos imaginários coerentes, dotados de temáticas redundantes ou obsedantes, de situações actanciais dominantes (separar, unir, reciclar) criadas pelas estruturas antropológicas” (Teixeira, 1999b: 78). Assim, podemos afirmar que a prática simbólica dos canais no YouTube e a imagem dos youtubers estão presentes de forma recorrente e pregnante no imaginário infantil o que denota a ética da estética contemporânea.

\footnotetext{
${ }^{4}$ Para levantamento de mais dados a respeito da temática e desta possibilidade, estamos desenvolvendo, em 2017, o projeto de pesquisa de iniciação científica intitulado "A imagem da descontração: proposição de um canal infanto-juvenil no youtube como prática de motivação pedagógica”, aprovado no Programa Unisul de Iniciação Científica.
} 


\section{Referências}

AZEVEDO, Nyrma Souza Nunes de. Pesquisa e reflexões sobre redes sociais. In AZEVEDO, Nyrma Souza Nunes de; SCOFANO, Reuber Gerbase. Estilhaços do Imaginário. Campinas: Alínea, 2016.

BOURDIEU, Pierre. As regras da arte. São Paulo: Companhia das Letras, 1996.

DEBORD, Guy. A sociedade do espetáculo. São Paulo: Contraponto, 1998.

DURAND, Gilbert. As estruturas antropológicas do imaginário. São Paulo: Martins Fontes, 2002. 1996.

Campos do Imaginário. Textos reunidos por Danièle Chauvin. Grenoble: Ellug,

JOHNSON, Steve. Cultura da interface: como o computador transforma nossa maneira de criar e comunicar. Rio de Janeiro: Jorge Zahar, 2001.

KAULING, G. B; MORAES, H.J.P. Identidade, identificação e imaginário: o exemplo de Du E-holic - o chapeleiro. Revista Memorare, Tubarão, SC, v. 2, n. 3, p.3-17, maio./ago.2015.

LUBA. Entrevista pessoal à pesquisadora. 2016.

LUBATV. Disponível em http://lubatv.com.br/ Acesso em maio de 2017.

MAFFESOLI, Michel. A contemplação do mundo. Porto Alegre: Artes e Ofícios, 1995. . No fundo das aparências. 2.ed. Petrópolis: Vozes, 1999.

. O conhecimento comum. Porto Alegre: Sulina, 2010.

- O imaginário é uma realidade. Entrevista a Juremir Machado da Silva. In: Revista

Famecos: mídia, cultura e tecnologia. Porto Alegre, n. 15, ago. 2001.

O ritmo da vida: variações sobre o imaginário pós-moderno. Rio de Janeiro:

Record, 2007.

Perspectivas tribais ou a mudança de paradigma social. Revista Famecos: mídia, cultura e tecnologia. Porto Alegre, n. 23, p. 23-29, abr. 2004.

MARTINO, Luiz Mauro Sá. Estética da comunicação. São Paulo: Vozes, 2007.

MONTEIRO, Aline Veríssimo; LIMA, Carolina Nóbrega; SILVA, Patrícia Reis Ferreira da. Uma experiência com Stop Motion em sala de aula: refletindo sobre imagem na educação escolar contemporânea. In AZEVEDO, Nyrma Souza Nunes de; SCOFANO, Reuber Gerbase. Estilhaços do Imaginário. Campinas: Alínea, 2016.

MORAES, Heloisa Juncklaus Preis. A descoberta e a vivência do virtual: experiências infantis. Florianópolis: Dioesc, 2012.

SERRES, Michel. Polegarzinha. Rio de Janeiro: Bertrand Brasil, 2013.

SILVA, Juremir Machado da. Tecnologias do imaginário. Porto Alegre: Sulina, 2006.

SOUZA, Carla C. Silveira de. Representações Sociais, Imaginário, Cotidiano e Escola. In: AZEVEDO, Nyrma N. de e SCOFANO, Reuber Gerbasi (orgs.) Estilhaços do Imaginário. Campinas: Alínea, 2009.

STRÔNGOLI, Maria Thereza in SANTOS, Dulce O. Amarante; TURCHI, Maria Zaira (orgs). Encruzilhadas do Imaginário: ensaios de literatura e história. Goiânia: Cânone Editorial, 2003.

TEIXEIRA, Maria Cecília Sanchez. Imaginário e Cultura: a organização do real. In: TEIXEIRA, Maria Cecília Sanchez; PORTO, Maria do Rosário S. Imaginário, cultura e educação. São Paulo: Plêiade, 1999a.

Imaginário e ideário no discurso pedagógico de Anísio Teixeira e Paulo Freire. In ARAÚJO, Alberto Filipe; MAGALHÃES, Justino. História, Educação e Imaginário. Lisboa: Universidade do Minho, 1999b. 
WUNENBURGER, Jean-Jacques; ARAÚJO, Alberto Filipe. Educação e Imaginário: introdução a uma filosofia do imaginário educacional. SP: Cortez, 2006.

Recebido em: 26/05/2017. Aprovado em: 14/07/2017. 